\title{
Metodología para el análisis de los discursos presidenciales como narraciones mediadoras
}

\author{
Methodology for the analysis of presidential \\ discourses as mediators narrations \\ Beatriz GÓMEZ VILLANUEVA \\ Secretaría de Educación Pública (SEP) - México \\ begovi23@yahoo.com.mx
}

\begin{abstract}
Cómo citar este artículo: Gómez VillanueVA, Beatriz (2016): «Metodología para el análisis de los discursos presidenciales como narraciones mediadoras», Mediaciones Sociales, no 15 , pp. 17-35. DOI: http://dx.doi.org/10.5209/MESO.54541
\end{abstract}

Recibido: 15 de septiembre de 2016.

Aceptado: 25 de octubre de 2016.

\section{RESUMEN}

El planteamiento metodológico que ofrece la mediación social para el análisis de los discursos políticos es el objeto de estudio del presente artículo. Las representaciones generadas por los gobiernos mexicanos manifestados en sus informes como parte de su rendición de cuentas, son vistas desde la óptica de la mediación cognitiva para entender cómo se interpretan los aconteceres y cómo se comunican. Si bien la construcción de las representaciones colectivas es multifactorial, en este caso se acude a los referentes gubernamentales. Su valor estriba en que el ejercicio del poder en México se fundamentó en el imaginario de la Revolución ininterrumpida, el que otorgó legitimidad al monopartidismo que imperó por más de 70 años en el país. Este artículo ofrece, además, un anexo en el que se desarrolla una minuciosa revisión de investigaciones sustentadas en las mediaciones comunicativas.

PALABRAS CLAVE: discursos presidenciales, mediación comunicativa, principios, temas, situaciones.

\section{ABSTRACT}

The object of the present paper is the methodological approach offered by the social mediation for the analysis of political discourses. The representations generated by Mexican governments in their discourses, for their performance accountability, are considered from the point of view of the 
cognitive mediation, in order to understand how the events are interpreted and how they are communicated. So we resort to study government referents even though the construction of collective representations is determined by many factors. Their value lies on the fact that the exercise of power in Mexico is based on the imagery of the uninterrupted Revolution, which gave legitimacy to the single party system that ruled in the country for more than 70 year. Besides, this paper offers an annex which displays a thorough review of studies dealing with communicative mediations.

KEYWORDS: presidential discourses, communicative mediation, principles, themes, situations.

Sumario: 1. Introducción. 2. Fundamentos epistemológicos. 3. La metodología de análisis de los discursos presidenciales como narraciones mediadoras que se ha aplicado en la tesis La inserción del discurso nacionalista en la retórica del gobierno mexicano (1939-1948 y 1983-2002). 4. El análisis de la mediación cognitiva en los relatos presidenciales. 5. Resumen. Bibliografía. Anexo: Principales investigaciones y publicaciones para el análisis de contenido de los relatos que cumplen funciones mediadoras.

\section{INTRODUCCIÓN}

La construcción de las representaciones que se han desarrollado en México para asumir una identidad nacional ha supuesto el concurso de factores diversos. En los albores del siglo XX, tras la Revolución Mexicana que inició en 1910, los grupos políticos beneficiados por el movimiento armado asumieron el poder gubernamental, y su discurso se convirtió en uno de los principales referentes que caracterizaron un concepto de nacionalismo que intentó integrar a una sociedad heterogénea y desarticulada. El análisis de contenido de ese discurso, proveniente del mensaje político de los informes de gobierno de los presidentes mexicanos, es el objeto de estudio de la investigación que sirvió de base a mi tesis doctoral ${ }^{1}$. Este artículo se deriva de ese estudio y su abordaje metodológico es una alternativa respecto al desarrollo de otro tipo de análisis políticos.

En la década de los 30 del siglo XX, tras la investidura gubernamental del general Lázaro Cárdenas, se formalizó la rendición de cuentas de forma anual para informar sobre el estado de la nación. En un segmento del discurso se asumía una postura ideológica en la que dominaron los preceptos de la gesta revolucionaria como aquéllos que justificaban toda acción de gobierno. Tanto en la etapa posrevolucionaria, de reconstrucción nacional, como en la neoliberal, de apertura económica, el icono de la Revolución fue el referente que dominó en ambos periodos de monopartidismo. El Partido Revolucionario Institucional (PRI) en una época y otra entendió que el ejerci-

1 La inserción del discurso nacionalista en la retórica del gobierno mexicano (1939-1948 y 1983-2002), dirigida por el profesor Dr. Manuel Martín Serrano. 
cio de gobierno y la actuación ciudadana habrían de ser acordes al nacionalismo revolucionario.

En este artículo sólo se describe la metodología que estudia 30 mensajes políticos de siete presidentes, seis priistas y uno de la oposición, Vicente Fox, quien inició el siglo XXI con altas expectativas, desmarcado ya del referente revolucionario. Y se ofrece un análisis de la mediación cognitiva en el que esos discursos presidenciales se examinan como relatos con temas o unidades mínimas de análisis, que refieren un particular objeto de referencia. De allí se deriva una situación o argumentación que es valorada por determinados principios. Un ejemplo real extraído del estudio que precede a este artículo y que corresponde al presidente Carlos Salinas de Gortari (1988-1994) señala: Ante la inminente emergencia de un México que habría de trascender el subdesarrollo, como parte de la situación Planteamiento de principios políticos, es necesario "Modernizar para asegurar la permanencia soberana de México", y "Reformar la Revolución a través de lo mejor del liberalismo social". Lo anterior bajo el principio del cambio.

La investigación que ha servido de base para este artículo ha sido concebida como parte de un proyecto científico, que se viene desarrollando en el ámbito de los estudios de la mediación social. Se trata de saber cuáles son las estructuras de representación que permanecen y que se transforman al hilo de los cambios sociohistóricos, en relatos procedentes de comunidades diversas y producidos en épocas diferentes El profesor Martín Serrano lo enlaza con la propuesta y con las aplicaciones del análisis de contenido que ha llevado a cabo Claude Lévi-Strauss en el ámbito de la Antropología Cultural.

Finalmente, en el presente texto se formulan los fundamentos epistemológicos, la metodología de análisis de los discursos políticos, el análisis de la mediación cognitiva y una exhaustiva descripción de los estudios realizados en la línea de las mediaciones comunicativas. Se comienza con los trabajos desarrollados por el Dr. Manuel Martín Serrano y se continúa con otros desde la misma perspectiva, elaborados por diversos autores.

\section{FUNDAMENTOS EPISTEMOLÓGICOS}

En las líneas que siguen se expone el método que se ha aplicado para identificar las representaciones del País y de su tiempo, que los presidentes mexicanos han difundido en sus discursos para dar cuenta del estado de la Nación. Es una metodología que se ha desarrollado para identificar mediaciones comunicativas. Concretamente, las mediaciones que operan con las representaciones que se ofrecen en los relatos, del estado del mundo y de lo que acontece. Como se sabe, esta metodología de aná- 
lisis de contenido, creada por Martín Serrano, constituye la parte aplicada del Paradigma de la Mediación. La metodología para investigar las mediaciones cognitivas y concretamente su expresión en las mediaciones comunicativas está descrita en varias publicaciones del autor ${ }^{2}$. En la exposición que sigue, se recogen los conceptos que, a mi juicio, son necesarios para explicar cómo se ha diseñado y se ha realizado el análisis de contenido de los discursos presidenciales. A pie de página se indican las fuentes.

\section{LA METODOLOGÍA DE ANÁLISIS DE LOS DISCURSOS PRESIDENCIALES COMO NARRACIONES ME- DIADORAS QUE SE HA APLICADO EN LA TESIS LA INSERCIÓN DEL DISCURSO NACIONALISTA EN LA RETÓRICA DEL GOBIERNO MEXICANO (1939-1948 Y 1983-2002)}

Los discursos presidenciales son relatos que, en este caso, se han difundido oralmente y se han transcrito en textos impresos. Como todos los relatos, tienen que descomponerse en un conjunto de unidades para proceder al análisis de sus contenidos. La metodología que se ha utilizado descompone las narraciones en "Temas". El tema consiste en

«la unidad de análisis mínima en la que cabe identificar una práctica mediadora. (...) [En un tema] todavía se conserva un argumento completo -o si se prefiere, "un mensaje"que se puede entender en sí mismo, con independencia de los restantes contenidos. (...) Los temas son las unidades más elementales en las que cabe descomponer las visiones del mundo, a un nivel en el que todavía se puede reconocer una interpretación del acontecer dotada de sentido social» (Martín Serrano, 2004: 217 y ss.).

Cada tema tiene la siguiente estructura narrativa:

1) Se refiere a un determinado OBJETO DE REFERENCIA, que es aquello a propósito de lo que trata el tema (Martín Serrano, 2004: 222) ${ }^{4}$.

2 Puede analizarse la mediación cognitiva utilizando el modelo canónico que se ha elaborado en Martín Serrano (1986: 147).

3 Manuel Martín Serrano diseña y aplica esta metodología por primer vez en 1974 en L'Ordre du Monde a travers la TV. Structure du discours électronique. Desde entonces está descrita y aplicada en numerosas publicaciones del autor y de sus discípulos. Las citas que se recogen en este epígrafe proceden de $L a$ producción social de comunicación en los capítulos referidos a "La producción del acontecer público y la elaboración de representaciones del entorno". Se cita por la paginación correspondiente a la 3a edición del libro (año 2004). Se identifica como (Martín Serrano, 2004).

4 “"OBJETO DE REFERENCIA DE LA COMUNICACION». Es la entidad a propósito de la cual se comunica. Entre los hombres cabe comunicar a propósito de entes que existieron, existen o existirán (cosas de la naturaleza, objetos fabricados, vegetales, animales, seres humanos); a propósito de entes que ni existieron, ni existen ni existirán (entes de ficción o míticos, seres imposibles, a los que se les atribuye el carácter de cosas, objetos o de seres vivos); a propósito de cualidades, manifestaciones, relaciones, acciones, sean observadas o inobservables, concebibles o inconcebibles; las cuales se les asignan a cualquier ente real o ideal, individual o colectivo, posible o imposible" (Martín Serrano, 2004: 224-225) (Cf. en La producción social de comunicación, epígrafe "Preparación de los productos comunicativos para la identificación de los temas y el análisis de las 
Por ejemplo: Un objeto de referencia, en el discurso del Presidente Lázaro Cárdenas, al final de la década de los años 30 del siglo XX, fue LOS RECURSOS EN HIDROCARBUROS DE MÉXICO.

2) Por ser objeto de la comunicación el OBJETO DE REFERENCIA es mencionado en ella, pero no pertenece al sistema comunicativo (SC). EI OBJETO DE REFERENCIA permanece en el exterior como un componente del sistema de los referentes $(\mathrm{SR})^{5}$. En la exposición, se mencionan ciertos datos a propósito del objeto de referencia (entre otros posibles datos de referencia) (Martín Serrano, 2004: 224).

Esos datos a propósito del objeto de referencia de la comunicación presentan a dicho objeto en una determinada "SITUACIÓN" (ibídem: 219).

En el mismo ejemplo: "La SITUACIÓN" que se presenta es: LOS RECURSOS EN HIDROCARBUROS DE MÉXICO "están en manos de multinacionales extranjeras y tienen que ser nacionalizados".

La descripción de una "SITUACIÓN" -como la que acaba de escribirse- es, desde el punto de vista narrativo, una argumentación. Toda argumentación expone un razonamiento, que incluye unos antecedentes, de los que se deriva una determinada conclusión $n^{7}$. En los discursos políticos, por lo general la conclusión a la que se quiere llegar predetermina los antecedentes que se mencionan en la "SITUACIÓN". Véase en el mismo ejemplo que se ha elegido:

prácticas mediadoras" (Martín Serrano, 2004: 222 y ss.). También existe un análisis sistemático de los conceptos de "Objetos de referencia" y de "Datos de referencia" en el tema 10 del libro Teoría de la comunicación. Epistemología y análisis de la referencia (Martín Serrano et al., 1982).

5 "La exterioridad del OBJETO DE REFERENCIA respecto a (SC) significa que en la comunicación todos los OBJETOS DE REFERENCIA se distinguen de todos los componentes del Sistema Comunicativo. Los OBJETOS DE REFERENCIA no equivalen ni a los Sujetos de la comunicación (los Comunicantes, p.e. Emisores y Receptores); ni a las materias comunicativas (sustancias expresivas, como p. e., el papel; expresiones, como p.e. el trazo de escritura); ni a los instrumentos de la comunicación (amplificadores, como p.e. el tam-tam, o los medios traductores, como p.e. la radio); ni a las representaciones cognitivas que los Comunicantes se hacen respecto a los objetos a propósito de los que comunican. También los componentes del propio Sistema de Comunicación o del proceso comunicativo pueden ser OBJETO DE REFERENCIA de la comunicación: p.e. cuando en el relato de la Prensa se comunica a propósito de EL LECTOR QUE ESTÁ LEYENDO ESE PERIÓDICO. Se comprende que «EL LECTOR» asume una nueva función referencial en el marco de una metacomunicación, sin perder su papel de Receptor en el marco del proceso comunicativo" (Martín Serrano, 2004: 225).

6 “"PLANO DE LA SITUACION de referencia a propósito de la que se comunica»: le pertenece cualquier emergente (...) que por su existencia o inexistencia, su presencia o su ausencia, su transformación o su permanencia, afecta o puede afectar a toda la comunidad, o bien a alguno o algunos de sus miembros. Recuérdese que el término "emergente» se refiere a todo lo que ocurre (o deja de ocurrir) en el entorno físico, social y gnoseológico de referencia, cualesquiera que sean su naturaleza, sus causas y sus efectos" (Martín Serrano, 2004: 219).

${ }^{7}$ Cf: Sobre la estructura lógica de los temas y sus análisis, el texto más completo es Bernete y Velarde (2014). 
El Presidente expone como antecedentes de "LA SITUACIÓN" un estado de cosas que se refieren a LOS RECURSOS EN HIDROCARBUROS DE MÉXICO. Concretamente, que "están en manos de multinacionales extranjeras". Esa presentación de los hechos está elaborada desde la perspectiva de una acción gubernamental concreta (que es la conclusión del razonamiento). Concretamente presenta la siguiente conclusión: (dada esa SITUACIÓN) LOS RECURSOS "tienen que ser nacionalizados". Este proceder argumentativo convierte la nacionalización en la consecuencia (necesaria, lógica, inevitable...) del estado de cosas que se describieron en los antecedentes.

El tema relaciona esa "SITUACIÓN" con algún $<$ PRINCIPIO $>$. EL $\langle$ PRINCIPIO $>$ le permite al mediador evaluar lo que acontece en una determinada "SITUACIÓN" como bueno o malo, legítimo o ilegítimo, conveniente o inconveniente, verdadero o falso, general o particular, normal o excepcional, importante o intranscendente, etc.

Estos criterios se denominan <PRINCIPIOS> porque preceden a la existencia de LA SITUACIÓN y (a juicio del mediador) no están condicionados por ella:

Al Plano de <LOS PRINCIPIOS> «le pertenece cualquier constancia (norma, aspiración, idea, modos establecidos de ser, de aparecer, de reaccionar, de hacer, de utilizar, de comportarse, de relacionarse; sean las cosas, los objetos, los sucesos, los seres vivos, las organizaciones, instituciones, las personas o las colectividades, etc.)» (Martín Serrano, 2004: 219).

En los discursos políticos que se han analizado en la tesis referida, se suele traer a colación <PRINCIPIOS> que legitiman, justifican, exigen la actuación que ha propuesto el Presidente, los cuales se presentan como criterios de valoración que estén vigentes en la comunidad. En el mismo ejemplo, se invoca, concretamente, el <PRINCIPIO > de <la soberanía nacional>.

El tema que ha servido de ejemplo, tiene la siguiente estructura narrativa:

LOS RECURSOS EN HIDROCARBUROS DE MÉXICO,

"están en manos de multinacionales extranjeras y tienen que ser nacionalizados" <porque así lo requiere la recuperación de las soberanía nacional>

Como se puede comprobar:

La construcción de un tema es una actividad de mediación. El mediador integra en una misma representación de lo que acontece:

a) Un determinado OBJETO DE REFERENCIA, que ha seleccionado entre todos los otros objetos a los que podía referirse. 
b) Podría presentar múltiples "SITUACIONES", de las que va a describir una concreta.

c) Va a relacionar esa "SITUACIÓN" con $\leq$ Un PRINCIPIO > entre todos los que estén vigentes.

Por lo tanto, y tal como quedó escrito, el tema es, al tiempo, una unidad narrativa y la unidad mínima en la que cabe identificar una práctica mediadora.

\section{Aplicaciones mediadoras de los temas}

Los mediadores operan con los temas para exponer dos tipos de argumentaciones:

1) Indican si un cambio (o una persistencia) de una SITUACION tiene (o no tiene) consecuencias para la vigencia (u obsolescencia) de algún PRINCIPIO. Véase con un nuevo ejemplo, procedente del discurso del Presidente Salinas, al finalizar la década de los 80 del siglo pasado:

"Avanzar en el progreso político y económico es necesario para" <conservar los ideales de la Revolución>.

2) Alternativamente, utilizan los temas para indicar si la transformación (o el mantenimiento) de algún <PRINCIPIO > tiene (o no tiene) consecuencias que cambien (o mantengan) "LA SITUACIÓN". Por ejemplo (tomado del Presidente de la Madrid):

$<$ La solidaridad de los mexicanos ha hecho posible> "que la población se organizase por sí misma para enfrentarse con los efectos del seísmo" (del terremoto que sufrió la Ciudad de México en 1985).

Se comprende que dos relatos pueden describir del mismo modo la SITUACIÓN y, sin embargo, elaborar temas diferentes, relacionando esa SITUACIÓN con $\angle \mathrm{PRINCI}$ PIOS $>$ distintos. Del mismo modo, relatos que remitan al mismo $<$ PRINCIPIO $>$ pueden desarrollar temas diferentes, relacionando esa evaluación con "SITUACIONES" distintas. La operación mediadora consiste precisamente en establecer una determinada conexión entre algo que se presenta cono "LA SITUACIÓN" de referencia y un <PRIN$\mathrm{CIPIO}>$ establecido, que reconocen todos los destinatarios. Aunque esa interpretación no sea necesariamente asumida por todos:

«La producción social de comunicación aparece, a la luz de estas reflexiones, como una actividad destinada a reproducir y producir una clase de representaciones sociales adecuadas para enfrentarse con el cambio de las condiciones objetivas que afronta la comunidad, manteniendo la validez de los principios más universales en los que se apoya la vida en común» (Martín Serrano, 2004: 217). 


\section{EL ANÁLISIS DE LA MEDIACIÓN COGNITIVA EN LOS RELATOS PRESIDENCIALES}

Como se ha explicado en este artículo, la investigación de la mediación cognitiva se inicia descomponiendo los relatos en temas. En cada tema, se lleva a cabo un análisis de contenido, que identifique su OBJETO DE REFERENCIA (es el PASO 10). Seguidamente, se toma nota de "LA SITUACIÓN" que se está describiendo y del $\angle \mathrm{PRINCI}$ $\mathrm{PIO}>$ que se esté invocando (PASO 2ㅇ). Se describen seguidamente:

(PASO 10): Identificar EL OBJETO DE REFERENCIA de cada tema es tarea sencilla, porque es la entidad a propósito de la que se está tratando.

(PASO 2): A tenor de lo que se ha expuesto, queda claro que en cada tema se utilizan y se relacionan datos que pertenecen a dos planos diferentes: unos, "AL PLANO DE SITUACIONES"; y otros, <AL PLANO DE LOS PRINCIPIOS>. Para identificar las características que les distinguen se aplican los siguientes protocolos:

*AI "PLANO DE LAS SITUACIONES en la que se presentan los objetos a propósito de la que se comunica" pertenece:

a) La información que se utiliza para identificar los referentes (p. e., "los Mexicanos"); para mencionar sus características (p. e., son "bravos", "nacionalistas"); para describir su estado ( $p$. e., están "protegidos" por el Ejército frente a los carteles de la droga); para contar lo que les acontece (p. e., resultan "extorsionados" por la policía).

b) La información que se refiere a todo lo que ocurre (o deja de ocurrir) en los entornos; cualquiera que sea su naturaleza, sus causas y sus efectos. Entre otras referencias, se mencionan situaciones que ocurren en el entorno físico, (p. e., un seísmo); en el económico (p. e., la devaluación del peso mexicano); en el ceremonial (p. e., el Centenario de la Independencia).

El repertorio de SITUACIONES diferentes que se han identificado en el corpus de los discursos presidenciales es muy numeroso. Para facilitar su análisis se han agrupado tomando en cuenta LOS OBJETOS DE REFERENCIA a los que corresponden.

*AI «PLANO DE LOS PRINCIPIOS de valoración de la situación de referencia» pertenece la información que utilice el mediador como criterio para evaluar cada SITUACIÓN y, por lo general, la forma en la que se la maneje. Se pueden valorar LAS SITUACIONES como <buenas o malas >, <legítimas o ilegítimas $>$, <convenientes o inconvenientes $\rangle$, <verdaderas o falsas $\rangle$, <normales o excepcionales $\rangle$, <importantes 0 intranscendentes $>$, etc. Los criterios de evaluación se reconocen porque

8 Proceden del capítulo de La mediación social "Fundamentos de una teoría de la comunicación por índex" (Martín Serrano, 2008: 119 y ss.). 
quien los utiliza considera que son válidos en todas LAS SITUACIONES o en SITUACIONES semejantes a la que se está describiendo o, al menos, en esa SITUACIÓN concreta.

Entre otros muchos criterios, en los discursos políticos suelen invocarse $<\mathrm{PRINCI}-$ PIOS> éticos (p. e., <la solidaridad>); jurídicos (p. e., <la legalidad vigente>); religiosos (p. e., <la fe en Cristo>); etnocéntricos (p. e., <el patriotismo>); raciales ( $p$. e., <la raza de bronce>); políticos (p. e., <la paz social >): existenciales (p. e.,<el bienestar familiar>); aspiraciones del Gobierno (p. e., <controlar la natalidad>).

Tanta dispersión de <PRINCIPIOS> requiere que se adopte algún procedimiento que permita agruparles en un repertorio reducido de tipologías. En los discursos políticos, es útil reunir los <PRINCIPIOS> que contienen valores alternativos en una misma PAUTA ${ }^{9}$. Por ejemplo, se puede establecer una Pauta con los principios que tienen que ver con <Estabilidad $>$ y los que tienen que ver con el <Cambio>.

\section{RESUMEN}

Como mencioné en la introducción, este artículo está basado en un estudio de las interpretaciones que han difundido los Presidentes de México del estado de la Nación y del acontecer político durante el periodo de sus respectivos mandatos. Abarca 30 años, durante los cuales se han sucedido dos periodos diferentes: uno posrevolucionario y otro el neoliberal.

Desde la perspectiva metodológica, este estudio ha pretendido mostrar unas actividades de mediación comunicativa, que se hacen explícitas en unos discursos políticos. Las interpretaciones de la realidad que proponen los Presidentes son mediaciones cognitivas. Son argumentaciones en las que el mediador construye unas "SITUACIONES" y las relaciona con los <PRINCIPIOS> que considera pertinentes. La exposición de cada argumentación requiere un tema. Por lo tanto, el repertorio de mediaciones cognitivas $\mathrm{o}$, si se quiere, de interpretaciones de la realidad que proponen los Presidentes coincide con el conjunto de los temas.

Dos ejemplos de lo anterior son las menciones de Miguel de la Madrid (19831988) y Vicente Fox (2000-2002). El primero menciona, a partir de la situación Obligaciones y responsabilidades del gobierno, "Aumentar la competitividad del aparato productivo nacional frente al exterior" y "Acelerar la descentralización de la vida na-

\footnotetext{
9 "Las Pautas" consisten en "dilemas" de valores. En la comunicación pública se opera con un repertorio de pautas cuyos principios se aplican según los temas. El profesor Martín Serrano los ha identificado y describe sus aplicaciones en el epígrafe "Las pautas obligaciones y deberes" de la primera edición de La producción social de comunicación (1986: 390-399). En esta investigación, también funcionan varias de esas pautas.
} 
cional" para ser afines al incipiente neoliberalismo que demandaba privatización y descentralización gubernamental, con base en el principio de la endogamia.

Desde el principio del cambio, Vicente Fox asume en su discurso el requerimiento internacional de integración y señala la importancia de "Emprender un renovado multilateralismo, sin menoscabo de la soberanía del Estado", así como "Generar un nuevo activismo en política exterior", como parte de la situación Relaciones con otros paises.

Martín Serrano diseñó las metodologías lógicas de las que proceden las técnicas de análisis que se han aplicado en esta investigación. La perspectiva metodológica se ha aplicado en un sinnúmero de investigaciones de los contenidos de la comunicación. Por tal motivo, después de enumerar la bibliografía, me ha parecido pertinente finalizar este artículo ofreciendo a los lectores un anexo en el que están relacionados los trabajos que analizan mediaciones comunicativas. La relación inicia con las obras de Martín Serrano y sigue con la de otros profesores e investigadores de su Universidad y de otras muchas, a las que se puede acceder en internet. Aunque sea una relación incompleta, deja constancia de la continuidad, diversidad y relevancia que ya tienen estos estudios. En base a ellos, las publicaciones teóricas relativas a las características y las aplicaciones de las mediaciones cognitivas y narrativas han alcanzado el desarrollo que es conocido.

\section{BiBLIOGRAFÍA}

BERNETE, F. y VELARDE, O. (2014): "Designs for Social Science Study of Globalized Future Scenarios", International Journal of Humanities and Social Science, vol. 4, no 11(1), pp. 93-108. Disponible en https://goo.gl/IgwRCk. Consultado el 8 de julio de 2016.

MARTíN SERRANO, M. (1974): L'Ordre du Monde a travers la TV. Structure du discours électronique. Lille: Universite de Lille III.

MARTíN SERRANO, M. et al. (1982): Teoría de la comunicación. I. Epistemología y análisis de la referencia. Madrid: A. Corazón.

MARTín SERRANO, M. (1986, 2004): La producción social de comunicación. Madrid: Alianza.

MARTín SERRANO, M. (2008): La mediación social. Madrid: Akal. 


\title{
ANEXO: PRINCIPALES INVESTIGACIONES Y PUBLICACIONES PARA EL ANÁLISIS DE CONTENIDO DE LOS RELATOS QUE CUMPLEN FUNCIONES MEDIADORAS
}

\author{
I. ANÁLISIS DE CONTENIDO \\ MARTÍN SERRANO, M. \\ "Las transformaciones históricas de las representaciones sociales de las cosas y de los objetos". \\ Utilizada en L'Ordre du Monde a travers la TV. Structure du discours électronique (Lille: Universi- \\ te de Lille III, 1974) y en La mediación social (Madrid: Akal, 1977).
}

(1970): Origen, situación, comportamiento, perspectivas y valores de 2.400 jóvenes. Madrid: Universidad Complutense de Madrid. Tesis doctoral.

(1969-1971): "Análisis del contenido de los programas de TV española". Investigaciones de base para el libro L'Ordre du Monde a travers la TV. Structure du discours électronique (1974).

(1971-1974): “Análisis de las visiones del mundo en la televisión". Investigación de base para el libro L'Ordre du Monde a travers la TV. Structure du discours électronique (1974).

(1971): "Identidades, vida y milagros en la visión del mundo de la comunidad de Bélmez de la Moraleda". Para el libro Sociología del milagro. Las caras de Bélmez (Barcelona: Barral, 1972).

(1975): "La representación del futuro deseado y esperado en el ámbito laboral, familiar, social y político". Utilizado en "Los españoles y el futuro. Prospectiva de la sociedad española en 1985", proyecto financiado por la Presidencia del Gobierno.

(1977-1979): "La imagen de los políticos españoles y sus transformaciones, cuando cambia el modelo político", Instituto de la Opinión Pública (ahora Centro de Investigaciones Sociológicas).

(1980): "Estructura del paro. Cómo se vive en el paro, cómo se piensa, cómo se representa el futuro", SEAF-PPO Ministerio de Trabajo.

(1981): "La imagen comunicativa de la televisión en relación con la de otros medios de comunicación", en García, J. (comp.): Radio Televisión Española y la Constitución. Madrid: Universidad Internacional Menéndez Pelayo, pp. 153-166.

(1981-1982): "Las funciones de los MCM, y las tipologías sociológicas de audiencias". Investigación de base para el libro El uso de la comunicación social por los españoles (Madrid: Centro de Investigaciones Sociológicas, 1982).

(1981-1986): “Los contenidos de la información pública en los medios impresos y audiovisuales. Comparación entre la producción narrativa de visiones del mundo durante el franquismo y la monarquía parlamentaria". Investigaciones de base para el libro La producción social de comunicación (Madrid: Alianza, 1986).

(1985): "Demandas comunicativas de los jóvenes". Utilizada para "Visión del mundo y uso de la información en los jóvenes", Revista de Estudios de Juventud, no 33, 1989, pp. 15-22.

(1987): "La participación de los medios audiovisuales en la construcción de la visión del mundo de los niños", Tecnología y Comunicación Educativas, no 6, pp. 33-45. Reeditado en Infancia y Sociedad, no 3, 1990, pp. 5-18.

(1991): "Autoimágenes, heteroimágenes generacionales, en las representaciones juveniles". Utilizada en el libro Los valores actuales de la juventud en España (Madrid, Instituto de la Juventud, 1991). 
(1991): "El uso social de la comunicación en España entre 1965-1990". Estudio diacrónico. Utilizado en "Las transformaciones sociales vinculadas a la era audiovisual" y en "Balance retrospectivo de la denominada era audiovisual", Centro de Investigaciones Sociológicas (CIS).

(1994): "Tres visiones del mundo, para cuatro generaciones de jóvenes", en Martín Serrano, M. (dir.): Historia de los cambios de mentalidades de los jóvenes entre 1960-1990. Madrid: Instituto de la Juventud, pp. 15-49.

(1998): "La gesta y la parábola en los relatos de la comunicación pública" en VV.AA.: La lengua española y los medios de comunicación. Primer Congreso Internacional de la Lengua Española, Vol. I. España-México: Siglo XXI / Secretaria de Educación Pública / Instituto Cervantes, pp. 357375.

MARTÍN SERRANO, M., CEREZO B. y AGUILERA, M. J. (1981): "Autoimagen y heteroimágenes de los universitarios". Utilizado en el libro Los universitarios madrileños. Vida, afanes y creencias después de la dictadura (Madrid: Dirección General de Juventud, 1982).

MARTÍN SERRANO, M. y SOBRINO, M. A.

(1987): "La representación del futuro comunicativo en la población española". Utilizado en revisiones del libro La producción social de comunicación (Madrid: Alianza: 1986).

(1988): “Análisis de contenido de la literatura científica y técnica sobre el impacto de las nuevas tecnologías en la comunicación", RTV.

MARTÍN SERRANO, M. y VELARDE, O.

(1988): "La transformación de los usos sociales de la comunicación en España". Utilizado en "Las transformaciones sociales vinculadas a la era audiovisual" y en "Balance retrospectivo de la denominada era audiovisual".

(1996): "Visiones del mundo y representaciones sociales de la Juventud española". Utilizado en Informe Juventud en España 1996 (Madrid: Instituto de la Juventud, 1996).

(2000): "Las identidades y los horizontes existenciales de la juventud". Para Informe Juventud en España 2000 (Madrid: Instituto de la Juventu, 2001).

(1999-2000): "Historias de vida, autoimágenes y heteroimágenes de los menores violentados y violentadores". Utilizado en el libro Violencias sociales que implican a menores como víctimas o agresores (Defensa del Menor, 2004).

MARTÍN SERRANO, M., BERNETE, F. y VELARDE, O. (1991): "Los valores actuales de la juventud en España". Investigación base para el libro del mismo nombre (Madrid: Instituto de la Juventud).

MARTÍN SERRANO, M., BERNETE, F., VELARDE, O. y MARTÍN, M. (1990-1992): “La transformación de las mentalidades de la juventud desde 1960 a 1980". Utilizada en el libro Historia de los cambios de mentalidades de los jóvenes entre 1960-1980 (Madrid: Instituto de la Juventud, 1994).

MARTín SERRANO, M. (dir.), ALAMINOS, A., BERNETE, F., MARTíN, M., MUÑOZ, A., REQUENA, M. y VELARDE, O. (1994): Historia de los cambios de mentalidades de los jóvenes entre 1960-1980, Madrid: Instituto de la Juventud.

MARTÍN SERRANO, M. y MARTIN, F. (1994): "La sociedad lectora". Nuevo análisis de contenido para la investigación sociohistórica "Transformación de los usos sociales de la comunicación desde el nacimiento hasta el ocaso de la era audiovisual en la comunicación de masas" (Madrid: Fundesco). 
MARTÍN SERRANO, M., MARTÍN SERRANO, E. y BACA, V. (1993-1995): "Representaciones de los varones y de las mujeres en la publicidad y en los programas en vivo de la TV". Investigaciones de base para el libro Las mujeres y la publicidad. Nosotras y vosotros según nos ve la televisión (Madrid: Instituto de la Mujer, 1995).

MARTÍN SERRANO, M. y MARTíN SERRANO, E. (1998-1999): "La violencia contra las mujeres, sus causas, sus formas, sus consecuencias". Estudio base para el libro Las violencias cotidianas cuando las víctimas son las mujeres (Madrid: Instituto de la Mujer, 1999).

ARIAS, M. A. (1986): “Una aplicación del modelo dialéctico: el proceso de mediación estructural en la prensa escrita”, Revista Española de Investigaciones Sociológicas, № 33, pp. 175-186.

BALLESTEROS, B. (2012): “Análisis sociohistórico de los textos referidos a los efectos de las innovaciones en el sistema laboral". Investigación de base para la tesis doctoral Las tecnologías de la información y de la comunicación en los cambios laborales: análisis sociohistórico de 1970 a 2010 (2012).

BERNETE, F.

(1989): "Representaciones de las identidades nacionales en los libros de historia de los países ibéricos y latinoamericanos". Estudio de base para la tesis doctoral Los estereotipos de la Comunidad Iberoamericana. La representación de los personajes en los libros de texto de Historia (1990).

(2013): "Identidades y mediadores de la ciudadanía digital", en Sierra, F. (coord.): Ciudadanía, tecnología y cultura. Barcelona: Gedisa, pp. 151-180.

DEL PALACIO, C. (2014): "Labores de ritualización y mitificación en las secciones policiacas de tres periódicos de Veracruz a través de sus imágenes", Relaciones: Estudios de Historia y Sociedad, vol. 35, no 140, pp. 71-106.

GALVIS, C. A. y BOTERO, L. H. (2012): “Comunicación pública: mediaciones para la movilización social", Observatorio (OBS*), vol. 6, no 4, pp. 27-43.

GRUPO DE INVESTIGACIÓN «IDENTIDADES SOCIALES Y COMUNICACIÓN»:

(2010 -2013): "Las visiones del mundo en las narraciones de un futuro transformado por los usos sociales de las nuevas tecnologías". Análisis de contenido de los textos científicos y académicos. Utilizado en "La producción social de la comunicación y la reproducción social en la era de la globalización". Ministerio de Ciencia e Innovación. Difusión de resultados en:

VELARDE, O. y BALLESTEROS, B. (2015) "La implicación de las TIC en la humanización de la sociedad", Revista Opción, vol. 31, no 78, pp. 31-41.

VELARDE, O. y BERNETE, F. (2016): "La producción social de comunicación cuando el mundo se globaliza", Janus.net, vol. 7, № 2.

(2014-2015): "Análisis de contenido del discurso científico referido a las repercusiones de las TIC en los escenarios juveniles". Investigadora principal: Olivia Velarde. Universidad Complutense de Madrid.

(2016-2020) (en curso): “Los usos del tiempo relacionados con la virtualización. Transformaciones generacionales". Investigadores principales: Olivia Velarde y Manuel Martín Serrano. Ministerio de Ciencia e Innovación. 


\begin{abstract}
VELARDE, O.
(1989): "La representación mediada de las identidades en los niños de escuelas muy marginales y muy exclusivas de la ciudad de México". Investigación de base para la tesis doctoral La mediación de los medios de comunicación de masas en la construcción de las representaciones infantiles (1992).

(1992): "Los arquetipos de los MCM: héroes y antihéroes de los niños", Revista Española de Investigaciones Sociológicas, no 57, pp. 167- 178.

(1994): "Los valores en torno a la familia y a la sexualidad", en Martín Serrano, M. (dir.): Historia de los cambios de mentalidades de los Jóvenes entre 1960 y 1990. Madrid: Instituto de la Juventud, pp. 97-126.

(1998): "La dramatización de la cotidianidad en los reality shows", en VV.AA.: La lengua española y los medios de comunicación. Primer Congreso Internacional de la Lengua Española, Vol. II. España-México: Siglo XXI / Secretaria de Educación Pública / Instituto Cervantes, pp. 1.0291.042.

VELARDE, O. y JIMÉNEZ, R. (2003): Informe sobre los estudiantes de la Universidad Nacional Autónoma de México y los de la Universidad Iberoamericana. México, D. F.: Instituto de Investigaciones sociales de la UNAM.

VELARDE, O. y MARTÍN SERRANO, M. (2009): "Los mundos de las familias con hijos dependientes y sin pareja". Utilizado en el libro Convivir con hijos dependientes y sin pareja. Estudios para la equiparación de los nuevos modelos de familias madrileñas. Madrid: Ayuntamiento de Madrid.

VELARDE, O. y MARTín SERRANO, M. (2009): "Análisis de los relatos referidos a conflictos cotidianos en los hogares". Utilizado en libro Conflictos de la vida cotidiana que generan violencias en los hogares. Estudios en las familias madrileñas para la prevención de las violencias. Madrid: Ayuntamiento de Madrid.

YOUNIS, J. A.

(1992): "Las guerras en las mentes de los niños", Revista Española de Investigaciones Sociológicas, no 57, pp. 179-189.

(2007): “La participación de la prensa nacional en la construcción de la imagen social de los jóvenes", en Gázquez, J. J. (coord.): Situación actual y características de la violencia escolar. Grupo Editorial Universitario, pp. 223-228.
\end{abstract}

\title{
II. REFERENCIAS TEÓRICAS Y DESARROLLOS Y METODOLÓGICOS
}

MARTÍN SERRANO, M.

(1974): L'Ordre du Monde a travers la TV. Structure du discours électronique. Lille: Universite de Lille III. Presentación: "La structure du discours iconique a la télévision », disponible en Razón y Palabra, no 72, 2010, reproducida en francés y traducida al español.

(1974): "Nuevos métodos para la investigación de la estructura y la dinámica de la enculturización", Revista Española de Opinión Pública, no 37, pp. 23-83.

(1976): “El referente de la comunicación”, en Martín Serrano, M. (dir.): Métodos de análisis de contenido. Madrid: Dpto. de Comunicación, Facultad de Ciencias de la Información, Universidad Complutense de Madrid, pp. 7-82. 
(1977): La mediación social. Madrid: Akal. Edición conmemorativa del 30 aniversario en 2008 (incorpora prólogo del autor).

(1978): Métodos actuales de investigación social. Madrid: Akal.

(1978): "Un método lógico para analizar los significados: aplicación al estudio del lenguaje de la TV", Revista Española de Investigaciones Sociológicas, no 2, pp. 21-51.

(1978) (dir.): Monográfico sobre "Trabajos a propósito de otros métodos de investigación en ciencias sociales", Revista Española de Investigaciones Sociológicas, ㄲo 3.

(1980): Teoría de la Comunicación. I. Epistemología y análisis de la referencia. Madrid: Alberto Corazón. Incluye tres capítulos escritos por M. A. Arias, J. Gracia y J. L. Piñuel. Segunda edición (revisada) en 1982.

(1981): “Un modelo metodológico para investigar los efectos socioculturales de los media", Anàlisi, no 3, pp. 14-29.

(1982): "La influencia social de la televisión: II. Fuentes y métodos de estudio", Revista Española de Investigaciones Sociológicas, № 17, pp. 65-82.

(1984): "Mediación cognitiva y estructural". Extraído de "La mediación de los medios de comunicación", en Moragas, M. de (ed.): Sociología de la comunicación de masas. I: Escuelas y autores. Barcelona: Gustavo Gili, pp. 141-162.

(1986): La producción social de comunicación. Madrid: Alianza. Segunda edición (reformada) en 1993; tercera edición (reescrita) en 2004.

(1986): "Presentación de la teoría social de la comunicación", Revista Española de Investigaciones Sociológicas, no 33, pp. 15-34.

(1989): “Diseños para investigar la producción social de comunicación", Revista Española de Investigaciones Sociológicas, no 48, pp. 79-90.

(1992): "Los cambios acontecidos en las funciones de la comunicación y en el valor de la información”, Revista Española de Investigaciones Sociológicas, no 57, pp. 13-20.

(1994): "Examen y evaluación de los diseños y de los datos", en Martín Serrano, M. (dir.): Historia de los cambios de mentalidades de los jóvenes entre 1960-1990. Madrid: Instituto de la Juventud, pp. 259-302.

(1994): "Las transformaciones sociales vinculadas a la era audiovisual”, en Díaz Nosty, B. (dir.): Comunicación social 1995/Tendencias. Madrid: Fundesco, pp. 217-225.

(1997): "La mediación de los medios", en Martín Barbero, J. y Silva, A. (comps.): Proyectar la comunicación. Santa Fe de Bogotá: Tercer Mundo, pp. 137-156.

(1999): "Balance retrospectivo de la denominada era audiovisual, en VV.AA.: La era de la comunicación audiovisual". Adeje, Gran Canaria: Universidad de Verano.

(1999): "El discurso social sobre la juventud desde la transición política hasta hoy", en VV.AA.: La nueva condición juvenil y las políticas de juventud. Barcelona: Diputación de Barcelona, pp. 71-81.

(2007): "La transferencia de la ejecución a la indicación en los comportamientos humanos", en Teoría de la comunicación. La comunicación, la vida y la sociedad. Madrid: McGraw-Hill, pp. 191-195.

(2007): "La producción de teoría de la comunicación con procedimientos científicos", Razón y Palabra, no 59. Monográfico dedicado a Teoría de la comunicación. La comunicación, la vida y la sociedad. 
(2008): "La mediación social en la era de la globalización", en La mediación social. Edición conmemorativa del 30 aniversario. Madrid: Akal, pp. 9-27.

(2011) "Diseño del análisis de contenido de publicaciones científicas y académicas, en las que haya referencia a las TIC y los cambios sociohistóricos". Aplicado en la investigación I+D "La producción social de la comunicación y la reproducción social en la era de la globalización".

MARTÍN SERRANO, M. y VELARDE, O. (2015): "La mediación comunicativa de las identidades individuales y colectivas", Revista Latina de Comunicación Social, no 70, pp. 552-565.

ARIAS, M. A. (1986): "Métodos de análisis de actores en comunicación", Revista Internacional de Sociología, no 1, pp. 23-34.

BALLESTEROS, B. (2011): “Comunicación y cambio social. Una lectura de La producción social de comunicación de Manuel Martín Serrano", Razón y Palabra, no 75.

BALLESTEROS, B., FRANCO, D. y PEDRO, J. (2012): “El papel de las TIC en el EEES como motor para la transformación social", en VV.AA.: Reformulaciones en el ámbito de la innovación dentro del EEES. Madrid: Visión, pp. 33-54.

BERNETE, F. (1992): "El estudio de los estereotipos a través del análisis de relatos", Revista Española de Investigaciones Sociológicas, № 57, pp. 123-135.

BERNETE, F. y VELARDE, O. (2014): "Designs for Social Science Study of Globalized Future Scenarios", International Journal of Humanities and Social Science, vol. 4, no 11(1), pp. 93-108.

BISBAL, M. (2008): "El observador observado, o la realidad mediada por los medios y los periodistas", Mediaciones Sociales, no 2, pp. 13-33.

CARDOSO, J. (2007): "Presupuestos epistemológicos y vigencia de la teoría de la mediación socia", Mediaciones Sociales, no 1, pp. 129-153.

CARRAZCO, G. (2013): "Manuel Martín Serrano: pionero de un análisis teórico de todas las manifestaciones comunicativas", Universum, no 28, vol. 1, pp. 247-253.

DEL RíO, P. (1990): "The instrumental space of social mediation", Infancia y Aprendizaje, vol. 13, pp. 191-244.

FRANCO, D. (2011): "La mediación social de Manuel Martín Serrano en los estudios de comunicación”, Razón y Palabra, no 75.

FUENTES, R. (2007): “Mediaciones académicas e interfaces digitales para la circulación del conocimiento en Ciencias de la Comunicación", Mediaciones Sociales, no 1, pp. 155-174.

HUMERES, M. y MORALES, G. (2013): "Metodologías y técnicas para el estudio de la mediación social: un recorrido por sus posibilidades empíricas", en VV.AA.: Simposio Internacional sobre Política Científica en Comunicación. Vol. 4. Universidad de Valladolid, pp. 971-986.

MARTÍN BARBERO, J. (1987): De los medios a las mediaciones: comunicación, cultura y hegemonía. Bogotá: Andrés Bello.

MIKLOS, T. y ARROYO, M. (2014): "Tres nuevos modos de investigar la visión del mundo. Metodologías prospectivas creadas por Manuel Martín Serrano", en Miklos, T. y Arroyo, M. (coord.): El futuro a debate. Visiones y concreciones prospectivas. México, D.F. Limusa/Noriega.

MONEREO, C. (2007): "Hacia un nuevo paradigma del aprendizaje estratégico: el papel de la mediación social, el yo, y las emociones", Electronic Journal of Research in Educational Psychology, vol. 5, no 13, pp. 497-53. 
MUÑOZ, A. (1986): "Ritual folklórico y representaciones colectivas. Modelo de análisis comunicacional", Revista Española de Investigaciones Sociológicas, no 33, pp. 55-82.

MUÑOZ, A. y AVELLO, J. (2002): “La comunicación desamparada. Una revisión de paradojas en la cultura juvenil”, en Rodríguez, F. (comp.): Comunicación y cultura juvenil. Barcelona: Ariel, pp. 2166.

SERRANO, Rafael (2013): "El trabajo expresivo y el discurso del profesor", Revista de la Asociación de Sociología de la Educación, vol. 6, no 2, pp. 302 -323.

VELARDE, O., BERNETE, F. y FRANCO, D. (2015): "Paradigmas de los efectos de las TIC en la cultura y en el conocimiento", Revista Latina de Comunicación Social, no 70, pp. 347-380.

VELARDE, O. y BERNETE, F. (2016): "Innovaciones comunicativas y cambios de los sistemas socioeconómicos. Interpretaciones de sus efectos de los textos científicos", Revista de Estudios Sociales, ํo 56, pp. 67-79.

\section{TESIS DOCTORALES}

MUÑOZ, A. (1984): Las reglas de la expresión carnavalesca en Laza: aplicación del análisis estructural en antropología de la comunicación.

ARIAS, M. A. (1986): Los actores de la comunicación.

BERNETE, F. (1990): Los estereotipos de la Comunidad Iberoamericana. La representación de los personajes en los libros de texto de Historia.

ESCUDERO, I. (1991): Percepción del entorno físico y social en los niños. Representación de la casa.

VELARDE, O. (1992): La mediación de los medios de comunicación de masas en la construcción de las representaciones infantiles.

ALCOCEBA, J. A. (2000): La producción comunicativa de la referencia: un análisis mediacional de las noticias del teletexto en España.

PLAZA, J. (2005): Modelos de varón y mujer en las revistas femeninas para adolescentes. La representación de los famosos.

CARDOSO, J. (2005): El papel de los medios de comunicación en la construcción del acontecer público.

MEDINA, D. do R. (2006): Mediatizaçao da comunicaçao política: media, política e comunicaçao, a negociaçao do poder.

STEFANELLO, G. A. (2007): Análisis de contenido de los relatos de la prensa brasileña sobre la Amazonía en dictadura y democracia.

CADILLA, M. (2010): La documentación científica y técnica sobre juventud: análisis mediacional del Injuve y sus fondos documentales.

ULLOA, A. (2010): Contratos de pareja y dramaturgias de género de jóvenes de escasos recursos de la ciudad de México.

PINTO, M. C. (2012): La construcción de la referencia en torno al concepto de brecha digital en España.

BALLESTEROS, B. (2012): Las tecnologías de la información y de la comunicación en los cambios laborales: análisis sociohistórico de 1970 a 2010. 
FRANCO, D. (2012): La transferencia de los desajustes sociales a los sujetos individuales: un análisis desde la mediación social.

GRANADOS, W. H. (2013): Comunicación en tiempos de desastre: el caso del terremoto en ArmeniaQuindío.

SERRANO, R. (2013): Innovación educativa y comunicación.

BORRÁS, C. R. (2015): Estructuras elementales del relato oral: análisis lógico de un corpus de narraciones espontáneas sobre sucesos de vida cotidiana acaecidos en La Laguna y La Orotava.

LÓPEZ, C. (2015): Representaciones sobre virtualización y cambio social en la literatura académica.

HERNÁNDEZ, A. (2015): Interacciones y manifestaciones de la identidad a través de los blogs.

\section{PUBLICACIONES MONOGRÁFICAS}

REVISTA MEDIACIONES SOCIALES (Universidad Complutense de Madrid, Madrid, 2007, números 13). En 2007 se cumplió el 30 aniversario de la publicación de La mediación social. Hace balance de 30 años de estudios sobre mediaciones sociales (https://goo.gl/mGxzvj). Contiene contribuciones de 34 autores. Particularmente pertinente, es el primer tomo: I. Estudios teóricos y metodológicos.

REVISTA CHASQUI (CIESPAL, Quito, 2011, números 114-115). Monográfico dedicado a Manuel Martín Serrano. Edición impresa y digital (https://goo.gl/8avhhd). Los trabajos que son más pertinentes para esta tesis:

Martínez-Ramos, E.: "Los métodos para la investigación de las transformaciones de las sociedades", pp. 120-122.

González, J.: "Las relaciones entre las mutaciones sociales y los cambios en las representaciones", p. 159.

Sierra, F.: “La comunicación pública y los cambios socioculturales”, pp. 184-186.

Avello, J.: "Producción social de identidades", pp. 65 y 166.

READING EN ACCESO ABIERTO (E-PRINTS COMPLUTENSE) en los que se han recopilado, analizado y documentado las publicaciones del profesor Manuel Martín Serrano. A destacar en esta ocasión los reading sobre mediaciones (http://eprints.ucm.es/13287/), principalmente los referidos a mediaciones cognitivas y estructurales, y a mediaciones narrativas; así como los reading referidos a las metodologías de las ciencias sociales, sus técnicas y aplicaciones (http://eprints.ucm.es/13290/).

LOCALIZACIÓN DE RECURSOS ON-LINE PARA ANÁLISIS DE CONTENIDO. ES una elaboración del grupo de investigación «Identidades sociales y comunicación», volcada entre 2011 y 2013. Incluye cinco publicaciones disponibles en acceso abierto. Las más útiles desde el punto de vista de la confección de esta tesis son las siguientes:

"Recursos on-line que fundamentan los análisis lógicos de los relatos y desarrollan las aplicaciones técnicas" (http://eprints.ucm.es/24154/).

"Recursos on-line que fundamentan los análisis estructurales y discriminativos de contenido y desarrollan las aplicaciones técnicas" (http://eprints.ucm.es/24396/). 
Beatriz Gómez VilLanueva es doctoranda de la Universidad Complutense de Madrid. Ha trabajado en el Ministerio de Educación Pública en México, en la Universidad Nacional Autónoma de México, en la Casa Central de los Colegios La Salle. Es capacitadora, conferencista, educadora. Es experta en temas educativos y de salud mental, y sobre estas temáticas ha escrito libros y otros artículos en medios nacionales e internacionales. Correo electrónico: begovi23@yahoo.com.mx. 